\title{
Management of Intrauterine Device Migrated into the Bladder: A Case Report and Literature Review
}

\author{
A. K. Paré $\mathbb{D}^{1},{ }^{1}$ A. Ouattara, ${ }^{1}$ D. Yé, ${ }^{1}$ B. Kabré, ${ }^{1}$ A. Bako, ${ }^{1}$ B. M. Abubakar $\left(D,{ }^{2}\right.$ and T. Kambou ${ }^{1}$ \\ ${ }^{1}$ Department of Urology, Souro Sanou University Teaching Hospital, Bobo-Dioulasso, Burkina Faso \\ ${ }^{2}$ Department of Surgery, Federal Medical Center, PMB 02, Nguru, Yobe State, Nigeria
}

Correspondence should be addressed to A. K. Paré; boupare@yahoo.fr

Received 20 June 2020; Revised 28 September 2020; Accepted 19 October 2020; Published 31 October 2020

Academic Editor: Yankai Xia

Copyright (c) 2020 A. K. Paré et al. This is an open access article distributed under the Creative Commons Attribution License, which permits unrestricted use, distribution, and reproduction in any medium, provided the original work is properly cited.

Intrauterine device represents the most reversible method of contraceptive worldwide. Its insertion is a medical procedure not free from complication. We report a rare case of intravesical migration of a copper intrauterine device inserted 18 months earlier in a 28 -year-old multiparous woman. The patient presented with irritative lower urinary tract symptoms, and she was managed endoscopically. This case underscores the role of cystoscopy in irritative lower urinary tract symptoms post IUD insertion.

\section{Introduction}

Intrauterine device (IUD) is the commonest method of reversible contraception worldwide. It is used by approximately $14 \%$ of women due to its efficacy, safety, and low cost. There are two types of IUD, the hormonal IUD which releases levonorgestrel and the copper IUD (TCu $380 \mathrm{~A}$ ) which releases copper ions [1], the last one being the most available form and constitutes the fourth choice of IUD by women in childbearing age in Burkina Faso [2]. IUD is not free from complications; in fact, complication such as IUD migration is one the gynaecologist's challenges [3]. IUD migration is commonly into the abdominal cavity; however, migration into the adnexa, iliac vein, and broad ligament has been reported [4]. Intravesical migration is a rare complication of IUD [5]. We present a case of intravesical migration of TCu IUD inserted 18 months earlier in a 28 -year-old multiparous woman presenting with irritative lower urinary tract symptoms. The migrated IUD was retrieved endoscopically via cystoscopy.

\section{Case Presentation}

This was a 28 -year-old woman presenting with 1-month history of mainly irritative lower urinary tract symptoms, characterized by urinary urgency and frequency. The patient had a history of copper IUD (TCu 380A) placed 18 months earlier for contraceptive purpose. There was a past history of haematuria 1 year prior to presentation which was intermittent and terminal associated with clot but no necroturia. Haematuria was spontaneously resolved by excessive water intake. There was a history of amenorrhea according to the patient for 1 year and condom use during sexual intercourse. The clinical examination revealed tenderness in the hypogastric region and moderate inflammation of urethral meatus. The gynaecological examination was normal. Urine microscopy and culture were done and were negative for the infection. Abdominal and pelvic ultrasound showed hyperechoic intravesical lesion (Figure 1) in keeping with IUD. The diagnosis of IUD migration into the bladder was made. Laboratory investigations found normal values for serum creatinine, haemoglobin, and write blood cells. 


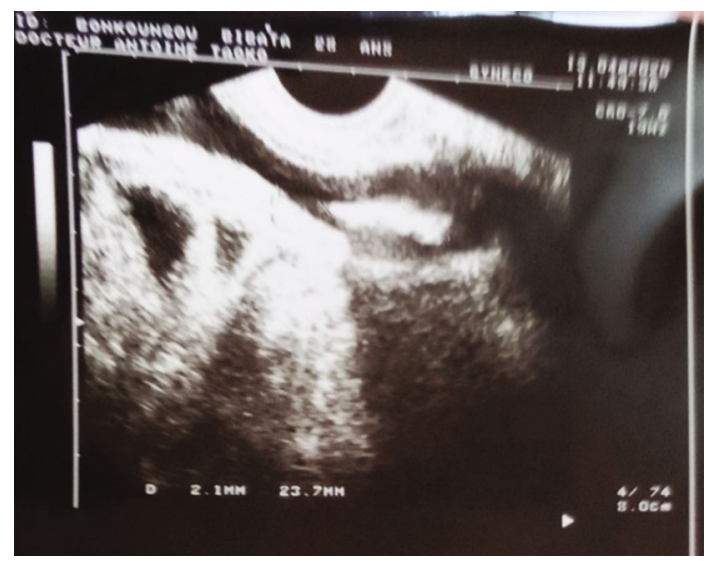

Figure 1: Hyperechoic image of intrauterine device in the bladder on pelvic ultrasonography.

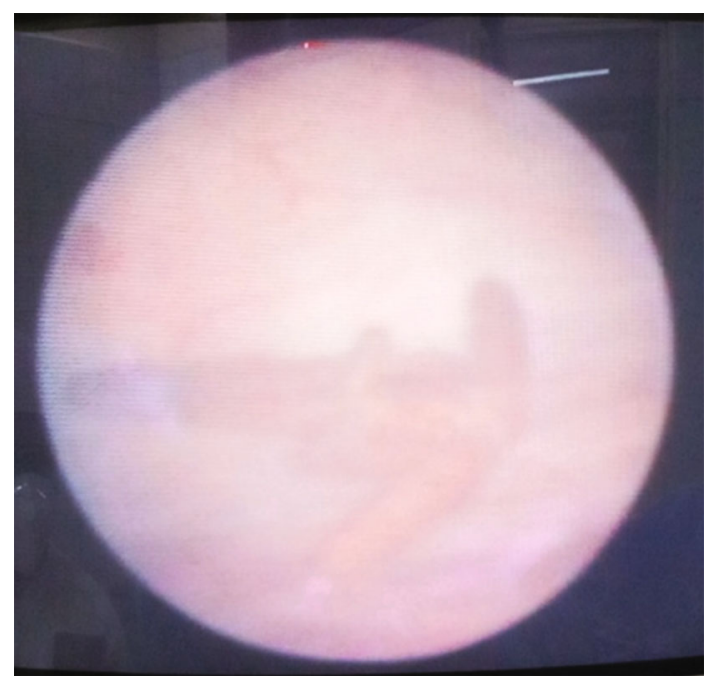

Figure 2: Cystoscopic vision of the intrauterine device with no damage to the bladder wall.

Cystoscopy was performed under local anaesthesia and antibiotic prophylaxis. The IUD was encrusted in the posterior bladder wall (Figure 2). The IUD was grasped with forceps and gently extracted (Figure 3 ) without any difficulty through the cystoscope (Figure 4). The postoperative management was uneventful. The patient was discharged the same day. She was seen 2 months post extraction with no any complaint. Pelvic ultrasound was done and was normal. Urine microscopy and culture were negative for the infection.

\section{Discussion}

Intrauterine device is the most popular method of reversible contraception in developing countries due to its efficiency and low cost $[1,2]$. During the preinsertion counselling, patients are not often informed about rare complications such as intravesical migration of the device. Hence, IUD migration may lead to medicolegal issues [6].

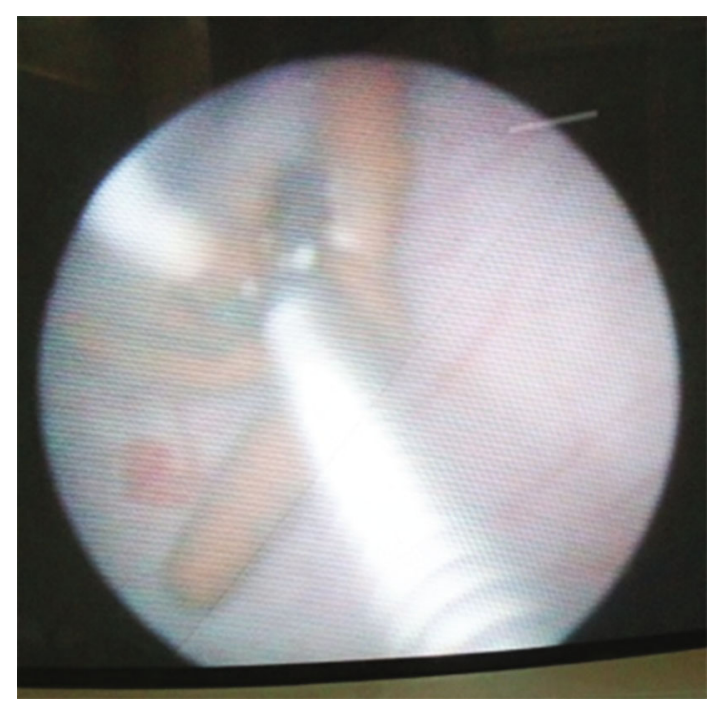

FIGURE 3: Intrauterine device grasped with forceps.

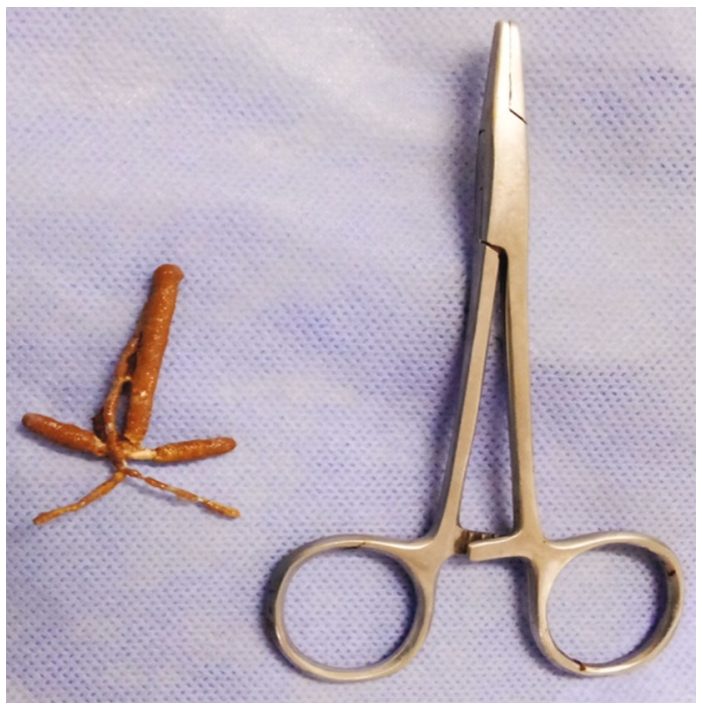

Figure 4: T-shaped intrauterine device completely extracted.

IUD migration into the structures adjacent to uterus is a rare complication with an estimated incidence of $1 / 1000$ insertions [3]. The literature mainly mentions some case reports and case series [4-7]. Goyal et al. in India, in a study of 240 copper-bearing IUDs inserted during a 12-month period, had reported only 2 cases of migration, including intravesical migration [7]. This case is our first experience for a 5-year urology practice.

Its insertion is a medical procedure for which preinsertion counselling often mentions common complications such as spotting, heavy periods, pelvic pain, infection, and the possibility of pregnancy as well. However, complications such as IUD migration are rarely mentioned.

IUD migration usually occurs following partial or complete uterine perforation during insertion. This makes this complication commoner in scared myometrium from 
previous surgeries and misdiagnosed hypoplastic uterus, retroverted, or hyperanteverted uterus. The migration is aided by local inflammation caused by the copper IUD [1].

The clinical presentation of migrated IUD may be incidental discovery during routine evaluation without any previous symptoms [7]. In contrary, the patient may present with lower urinary tract symptoms (LUTS), mainly storage symptoms with urgency, urinary frequency, haematuria, or per vaginal discharge $[8,9]$. Otherwise, urogenital fistula such as vesicouterine fistula may be the main presenting feature [10]. Bladder stones as complication of IUD migration into the bladder have also been reported causing obstructive (emptying phase) lower urinary tract symptoms, such as straining on micturition and acute retention of urine [11]. For the purpose of diagnosis, imaging, as well as endoscopy, may be required. Thus, bladder imaging can help to identify a foreign body in the bladder. Full bladder ultrasound, as in our case, allows the visualization of the IUD [12]. However, cystoscopy remains essential for a complete evaluation of the bladder. It may reveal the presence or absence of a foreign body such as calculus and also help in determining if the migration is partial or complete into the bladder [13]. A blue methylene test or cystography is often useful to rule out fistula.

The removal of the fully migrated IUD from the bladder is most often performed during cystoscopy [13], without difficulty in the cases seen early as in our case. In some cases, the removal is preceded by lithotripsy in the case of a calcified IUD. A cystotomy or even a laparotomy is sometimes necessary when an IUD migrated into the bladder and ascend into the ureter [14]. In some areas, herbal formula like Persian herbal recipe used to remove stones without open surgery (helped stone ejection or stone dissolution) [15]. In the case of a vesicouterine fistula, open surgery or laparoscopic surgery [16] remains the best treatment with an aim to close separately, both the bladder and uterine openings of the fistula, with or without preservation of the uterus.

\section{Conclusion}

IUD insertion is not a minor procedure. It requires regular monitoring to ensure its position. Serious complications such as intravesical migration are rare but are possible. Management is made easy with the aid of endoscopic evaluation and treatment.

\section{Ethical Approval}

Ethical approval was obtained from the local ethical committee.

\section{Consent}

Written consent was obtained from the patient for the publication of this case report and any accompanying images.

\section{Conflicts of Interest}

The authors declare that there are no conflicts of interest regarding the publication of this article.

\section{References}

[1] M. E. Ortiz and H. B. Croxatto, "Copper-T intrauterine device and levonorgestrel intrauterine system: biological bases of their mechanism of action," Contraception, vol. 75, no. 6, pp. S16-S30, 2007.

[2] R. L. Callahan, A. Brunie, A. C. L. Mackenzie et al., "Potential user interest in new long-acting contraceptives: results from a mixed methods study in Burkina Faso and Uganda," PLoS One, vol. 14, no. 5, p. e0217333, 2019.

[3] C. Varela, E. Siña, A. Rojas Astorga et al., "The walking IUDs," in The gynecologists nightmare, p. C-2334, ECR, 2017.

[4] A. Kallat, A. Ibrahimi, O. Fahsi et al., "Le dispositif intrautérin: à propos d'une complication rare et revue de la littérature," The Pan African Medical Journal, vol. 27, p. 193, 2017.

[5] V. Ceccato, A. Boileau, M. Roblin, D. Tariel, D. Bon, and V. Estrade, "Migration intravésicale d'un dispositif intrautérin. Stratégies d'exploration et modalités thérapeutiques," Progrès en Urologie, vol. 17, no. 2, pp. 256-259, 2007.

[6] L. Grimaldi, F. De Giorgio, P. Andreotta, M. C. D'Alessio, C. Piscicelli, and V. L. Pascali, "Medicolegal aspects of an unusual uterine perforation with multiload- $\mathrm{Cu} 375 \mathrm{R}$," The American Journal of Forensic Medicine and Pathology, vol. 26, no. 4, pp. 365-366, 2005.

[7] S. Goyal and G. S. Snigdha, "Displaced intrauterine device. A retrospective study," Journal of Medical Research, vol. 2, no. 2, pp. 41-43, 2016.

[8] P. L. Martínez-Valls, B. Honrubia Vilchez, A. Rodríguez Tardido et al., "Voiding symptoms as presentation of an intravesical foreign body," Archivos Españoles de Urología, vol. 61, no. 7, pp. 781-785, 2008.

[9] D. Schwartzwald, U. M. M. Mooppan, M. Leon Tancer, G. Gomez-Leon, and H. Kim, "Vesicouterine fistula with menouria: a complication from an intrauterine contraceptive device," The Journal of Urology, vol. 136, no. 5, pp. 10661067, 1986.

[10] B. C. Ozgur, O. G. Doluoglu, H. Sarici, M. M. Sunay, M. A. Karagoz, and M. Eroglu, "S277: intrauterine device migration to two different localizations resulting in bladder stone and carrying the risk of vesicovaginal fistula," European Urology Supplements, vol. 13, no. 7, p. e1591, 2014.

[11] Y. Nouira, S. Rakrouki, M. Gargouri, Z. Fitouri, and A. Horchani, "Intravesical migration of an intrauterine contraceptive device complicated by bladder stone: a report of six cases," International Urogynecology Journal, vol. 18, no. 5, pp. 575-578, 2007.

[12] N. Peri and D. Graham, "Imaging of intrauterine contraceptive devices," Journal of Ultrasound in Medicine, vol. 26, no. 10, pp. 1389-1401, 2007.

[13] M. Vahdat, M. Gorginzadeh, A. S. Mousavi, E. Afshari, and M. A. Ghaed, "Cystoscopic removal of a migrated intrauterine device to the bladder; a case report," Contraception and Reproductive Medicine, vol. 4, no. 1, 2019.

[14] A. Van Ophoven and J. B. De Kernion, "Clinical management of foreign bodies of the genitourinary tract," The Journal of Urology, vol. 164, no. 2, pp. 274-287, 2000. 
[15] A. Hosseinkhani, F. Tabatabaei, M. Mosaffa-Jahromi, and M. Pasalar, "Urinary bladder stone passing using Persian herbal recipe," Journal of Evidence-Based Integrative Medicine, vol. 23, pp. 1-4, 2018.

[16] N. N. Zhang, N. Zuo, T. S. Sun, and Q. Yang, "An effective method combining various endoscopes in the treatment of intravesical migrated intrauterine device," Journal of Minimally Invasive Gynecology, vol. 27, no. 3, p. 582, 2020. 